\title{
FOREWORD: CRISIS AND CAPITAL THE DARK SIDE OF RECOVERY
}

The immediate aftermath of disaster is frequently portrayed as a time of great solidarity, often across all the traditional lines, such as race and class, that divide people in complex societies. Disaster is also framed as the opportunity for change, to "build back better," to improve the lives of the victims, to address those features of a community that rendered people vulnerable to hazards. As many disaster chroniclers have noted, Dickens's ringing phrase "It was the best of times, it was the worst of times" could not be more apt. We do see the best in human beings and communities in immediate aftermaths. Moments of great courage, generosity, and nobility express the deep roots of human sociability.

That period of intense social solidarity, however, tends to be fragile and short-lived. The arrival of aid and the beginning of debates about the direction and form of reconstruction tend to dissipate the altruism of the early moments of post-impact solidarity. Entrenched interests soon emerge to restore their advantages temporarily suspended in the wake of catastrophe. In fact, much post-disaster reconstruction restores many of the social features that render people vulnerable to hazard onset. In a market society, as Steve Kroll-Smith notes, "How could it be otherwise?"

There is no lack of that irony in the compelling narratives and analyses of the 1906 San Francisco earthquake-fire and Hurricane Katrina at the turn of the twenty-first century in New Orleans that Steve Kroll-Smith skillfully weaves together in Recovering Inequality. He explores and demonstrates that the two cities, both lauded for their beauty and the wealth and diversity of their cultures, both situated within extremely exposed environments, privileged the accumulation of wealth over anything approaching basic security for their inhabitants.

The chapters roughly follow the trajectory of the catastrophes in both cities from the moments of impact and the stories of people helping people to the inevitable hysteria around looting, from the wicked capital-inspired algorithms of disaster assistance to the opportunistic efforts of elites and politicians in both cities to engage in "ethnic cleansing," seeking to rid themselves of social groups that were seen as inferior and consequently less deserving of assistance in the aftermath. Throughout, Kroll-Smith takes us on side trips through history that help elucidate the processes set in motion as the needs of the market easily outmaneuver empathy and fairness.

In this study of two iconic American cities and the aftermath of disas- 
ter, Kroll-Smith masterfully reveals how the process of post-disaster reconstruction reflects and expresses the fundamental tensions and contradictions in our social, economic, and environmental relations. Moreover, the narratives reveal the essential continuities between late-nineteenthcentury laissez-faire economics and early-twenty-first-century neoliberalism that inform the process of reconstruction to privilege accumulation by certain sectors of society over others.

Thus, neoliberal market logics and the eradication of most structural regulations or constraints today guide the decisions and choices made by governments, businesses, and now even nongovernmental organizations (NGOs) involved in recovery. In this context, human interests and market interests rarely coincide. The frequently chanted trope "Build back better" is far more a rhetorical gloss on the realpolitik of setting aright those pillars of inequality knocked about by disaster.

As I write, neoliberal versions of social and environmental relations are ubiquitous in current discourses, making alternative understandings extremely difficult to deploy, much less empower. Neoliberalism, as a model for relations between human beings and between human beings and the environment, is presented today as if designed by nature. Under such conditions it is reasonable to ask how any process of recovery can be socially just and environmentally secure.

"But it is ironic, is it not," Kroll-Smith observes at one point in the book, "that the human labor done in the name of disaster relief too often creates a suffering, a cruelty, that equals or exceeds that wrought by nature?" Recovering Inequality: Hurricane Katrina, the San Francisco Earthquake of 1906, and the Aftermath of Disaster throws a bright light on just this irony. 